\title{
PEMODELAN INDEKS PEMBANGUNAN MANUSIA (IPM) KOTA AMBON MENGGUNAKAN METODE STEPWISE
}

\section{(Model of Ambon City Human Development Index (HDI) Using Stepwise Method)}

\author{
Sanlly Joanne Latupeirissa ${ }^{1^{*}}$ Ronald John Djami $^{2}$ \\ Program Studi Statistika Jurusan Matematika FMIPA, Universitas Pattimura \\ Jalan Ir. M. Putuhena, Kampus Unpatti - Poka, Ambon, 97233, Maluku, Indonesia \\ e-mail: joannelatupeirissa@ymail.com ${ }^{1 *}$,ronalddjami@gmail.com ${ }^{2}$
}

\begin{abstract}
Abstrak: Indeks Pembangunan Manusia (IPM) merupakan salah satu indikator yang dapat digunakan untuk mengukur keberhasilan pembangunan nasional pada suatu wilayah. Tercatat sejak tahun 2010 IPM kota Ambon mengalami peningkatan dari 76,07 menjadi 79,82. Pada penelitian ini data IPM dan faktorfaktor yang diduga mempengaruhi dimodelkan dalam regresi linear menggunakan metode stepwise. Hasil pemodelan menunjukkan bahwa harapan lama sekolah dan pengeluaran perkapita berpengaruh signifikan terhadap IPM. Diperoleh model regresi linear berganda terbaik dimana tidak lagi terdapat masalah multikolinearitas dengan nilai $R^{2}$ sebesar 0,98 .
\end{abstract}

Kata Kunci : Indeks Pembangunan Manusia, Stepwise, Regresi Linear Berganda

\begin{abstract}
The Human Development Index (HDI) is one indicator that can be used to measure the success of national development in an area. Recorded since 2010 the HDI of Ambon city has increased from 76,07 to 7,.82. In this study HDI data and factors that are thought to influence are modeled in linear regression using the stepwise method. The results of modeling show that school year expectations and per capita expenditure have a significant effect on HDI. The best multiple linear regression model is obtained where there are no more multicollinearity problems with an $R^{2}$ of 0,98 .
\end{abstract}

Keywords: Human Development Index, Stepwise, Multiple Linear Regression

\section{PENDAHULUAN}

Salah satu tujuan nasional Bangsa Indonesia yakni memajukan kesejahteraan umum. Untuk mencapai tujuan tersebut maka salah satu usaha yang dilakukan adalah pembangunan nasional. Pembangunan perlu dilakukan secara menyeluruh dan berkelanjutan untuk meningkatkan kesejahteraan dan kualitas hidup masyarakat. Salah satu indikator yang dapat mengukur keberhasilan pembangunan nasional yaitu Indeks Pembangunan Manusia (IPM). IPM merupakan suatu pengukuran capaian pembangunan manusia yang didasarkan pada beberapa komponen dasar kualitas hidup, antara lain umur panjang, pengetahuan dan standar kehidupan yang layak [1].

Pada tahun 2017, Provinsi Maluku berada pada kategori sedang dengan angka 68,19. Angka ini menunjukkan bahwa pembangunan manusia di Provinsi Maluku mengalami peningkatan 0,59 persen dari tahun 2016 sebesar 67,60 [2]. Kota Ambon sebagai ibukota Provinsi Maluku merupakan kota dengan IPM tertinggi dibanding 10 kabupaten/kota lainnya di Provinsi Maluku. Sejak tahun 2010 IPM Kota Ambon mengalami peningkatan dari 76,07 menjadi 79,82 [3].

Copyright $\odot$ 2019: Author

Diterima:
45

https://ojs3.unpatti.ac.id/index.php/variance/ Disetujui: 
Latupeirissa, dkk $\mid$ Pemodelan Indeks Pembangunan Manusia (IPM) . . .

Salah satu analisis statistika yang dapat digunakan untuk memodelkan angka IPM yaitu regresi. Penelitian tentang IPM menggunakan regresi telah dilakukan oleh Loklomin pada tahun 2019, yaitu "Pemodelan Indeks Pembangunan Manusia di Kepulauan Maluku dengan Pendekatan Estimasi Interval Parameter Model Regresi Semiparametrik Spline Truncataed". Hasil penelitian tersebut menunjukkan bahwa kelompok usia sekolah di Perguruan Tinggi, jumlah sarana kesehatan, presentase rumah tangga dengan akses air bersih, presentase penduduk miskin dan presentase tingkat partisipasi angkatan kerja memiliki pengaruh terhadap IPM di Kepulauan Maluku [4].

Pemodelan IPM dengan tujuan mengetahui faktor-faktor yang mempengaruhinya juga dapat dilakukan menggunakan analisis regresi linear berganda. Pada pembentukan model regresi linear berganda seringkali muncul masalah multikolinearitas, yaitu terdapat hubungan linear yang sempurna atau korelasi yang tinggi antara variabel predictor [5]. Dalam hal multikolinearitas, ada beberapa cara untuk mendapatkan model terbaik. Pemilihan model terbaik dapat dilakukan dengan menggunakan metode stepwise [6]. Proses metode stepwise dilakukan dengan memasukkan satu per satu variabel prediktor yang memiliki nilai koefisien korelasi tertinggi ke dalam model.

Penelitian tentang penggunaan metode stepwise telah dilakukan oleh Hapsery dan Lubis tahun 2019 dengan memodelkan Track Quality Index (TQI) untuk kereta api semicepat Indonesia. Hasil penelitian menunjukkan bahwa pembentukan model regresi melalu tiga tahapan, dimana masalah multikolinearitas dapat teratasi dan model tersebut memiliki variabilitas data yang dapat dijelaskan sebesar 99,7\% [7].

Berdasarkan uraian di atas maka penelitian ini bertujuan untuk memodelkan IPM Kota Ambon dan variabel-variabel yang diduga mempengaruhinya. Pemodelan menggunakan regresi linear dengan metode stepwise untuk mendapatkan model terbaik yang tidak terdapat masalah multikolinearitas.

\section{METODOLOGI}

\subsection{Sumber dan Jenis Data}

Penelitian ini menggunakan data sekunder yang diperoleh dari BPS Kota Ambon, yaitu data IPM beserta faktor-faktor yang diduga mempengaruhi IPM Kota Ambon tahun 2010-2017.

\subsection{Variabel Penelitian}

Adapun variabel respon dan prediktor yang digunakan dalam penelitian ini sebagai berikut.

Tabel 1. Variabel Penelitian

\begin{tabular}{|l|l|}
\hline \multicolumn{1}{|c|}{ Variabel } & Skala \\
\hline Indeks Pembangunan Manusia $(\mathrm{Y})$ & Rasio \\
\hline Angka Harapan Hidup $\left(\mathrm{X}_{1}\right)$ & Rasio \\
\hline Rata-rata Lama Sekolah $\left(\mathrm{X}_{2}\right)$ & Rasio \\
\hline Harapan Lama Sekolah $\left(\mathrm{X}_{3}\right)$ & Rasio \\
\hline Pengeluaran per Kapita $\left(\mathrm{X}_{4}\right)$ & Rasio \\
\hline Presentase Penduduk Miskin $\left(\mathrm{X}_{5}\right)$ & Rasio \\
\hline
\end{tabular}

\subsection{Prosedur Analisis}

Adapun prosedur analisis data dalam penelitian ini sebagai berikut.

1) Melakukan analisis deskriptif terhadap data IPM (Y) dan faktor-faktor yang diduga mempengaruhinya $\left(\mathrm{X}_{\mathrm{i}}\right)$.

2) Melakukan deteksi multikolinearitas dengan menggunakan nilai VIF.

3) Membentuk persamaan regresi linear dengan metode stepwise:

a. Menghitung nilai koefisien korelasi antara semua variabel prediktor dan respon.

b. Meregresikan variabel prediktor yang memiliki nilai koefisien korelasi tertinggi dengan variabel respon. 
c. Melakukan pengujian signifikansi parameter secara simultan dan parsial. Jika hasil pengujian menunjukkan variabel prediktor berpengaruh terhadap variabel respon, maka tambahkan variabel prediktor lainnya sesuai langkah $\mathrm{b}$. Tetapi, jika hasil pengujian menunjukkan variabel prediktor tidak berpengaruh terhadap variabel respon, maka keluarkan variabel prediktor tersebut dari model.

d. Ulangi langkah a sampai c.

4) Melakukan kembali uji multikolinearitas dengan menggunakan nilai VIF.

5) Menghitung nilai koefisien determinasi.

6) Melakukan pengujian asumsi klasik regresi linear.

7) Menghitung nilai koefisien determinasi dari model yang terbentuk.

\section{HASIL DAN PEMBAHASAN}

\subsection{Analisis Deskriptif Variabel Penelitian}

Langkah pertama sebelum melakukan pemodelan, terlebuh dahulu melakukan analisis deskriptif untuk mengetahui karakteristik variabel penelitian. yang disajikan pada Tabel 2 sebagai berikut.

Tabel 2. Analisis Deskriptif Variabel Penelitian

\begin{tabular}{|l|c|c|c|}
\hline Variabel & Minimum & Mean & Maximum \\
\hline IPM $(\mathrm{Y})$ & 76.07 & 78.2725 & 79.82 \\
\hline AHH $\left(\mathrm{X}_{1}\right)$ & 68.66 & 69.2800 & 69.92 \\
\hline RLS $\left(\mathrm{X}_{2}\right)$ & 10.78 & 11.3700 & 11.65 \\
\hline HLS $\left(\mathrm{X}_{3}\right)$ & 14.64 & 15.4438 & 15.91 \\
\hline Pengeluaran Perkapita $\left(\mathrm{X}_{4}\right)$ & 12421 & 13065.56 & 13699 \\
\hline Persentase Penduduk Miskin $\left(\mathrm{X}_{5}\right)$ & 4.23 & 5.3263 & 7.67 \\
\hline
\end{tabular}

Tabel 2 menunjukkan bahwa variabel pengeluaran per kapita $\left(\mathrm{X}_{4}\right)$ memiliki rata-rata tertinggi yaitu sebesar $13065,56$.

\subsection{Deteksi Multikolinearitas}

Selanjutnya untuk mendeteksi adanya masalah multikolinearitas, digunakan nilai Variance Inflation Factor (VIF). Dikatakan terdapat masalah multikolinearitas jika nilai VIF lebih dari 10 [8]. Berikut nilai VIF setiap variabel prediktor.

Tabel 3. Nilai VIF Variabel Prediktor

\begin{tabular}{|l|c|}
\hline Variabel Prediktor & Nilai VIF \\
\hline AHH $\left(\mathrm{X}_{1}\right)$ & 176,180 \\
\hline RLS $\left(\mathrm{X}_{2}\right)$ & 565,324 \\
\hline HLS $\left(\mathrm{X}_{3}\right)$ & 234,232 \\
\hline Pengeluaran Perkapita $\left(\mathrm{X}_{4}\right)$ & 127,175 \\
\hline Persentase Penduduk Miskin $\left(\mathrm{X}_{5}\right)$ & 198,556 \\
\hline
\end{tabular}

Berdasarkan Tabel 3, masing-masing variabel prediktor memiliki nilai VIF yang besar, yaitu lebih dari 10. Hasil tersebut menunjukkan bahwa model mengalami kasus multikolinearitas atau adanya hubungan linear yang sempurna antara variabel prediktor, sehingga akan dilakukan penanganan dengan melakukan pemilihan model terbaik menggunakan metode stepwise pada regresi linear berganda.

\subsection{Metode Stepwise}

Model regresi dengan metode stepwise diperoleh melalui proses memasukkan satu per satu variabel bebas yang memiliki nilai koefisien korelasi tertinggi dengan variabel respon ke dalam model. Hasil analisis regresi dengan metode stepwise disajikan pada Tabel 4. 
Latupeirissa, dkk| Pemodelan Indeks Pembangunan Manusia (IPM) . .

Tabel 4. Pemilihan Variabel Bebas Berdasarkan Koefisien Korelasi

\begin{tabular}{|c|c|c|c|}
\hline Model & Variabel yang Masuk ke Model & Variabel yang Tersisa & Metode \\
\hline 1 & $\operatorname{HLS}\left(\mathrm{X}_{3}\right)$ & $\begin{array}{l}\text { AHH }\left(X_{1}\right), \text { RLS }\left(X_{2}\right), \text { Pengeluaran Perkapita } \\
\left(\mathrm{X}_{4}\right), \text { Persentase Penduduk Miskin }\left(X_{5}\right)\end{array}$ & \multirow{4}{*}{$\begin{array}{c}\text { Stepwise (Criteria: } \\
\text { Probability-of- } F- \\
\text { to-enter }<=.050, \\
\text { Probability-of- } F \text { - } \\
\text { to-remove } \\
>=.100) .\end{array}$} \\
\hline 2 & $\begin{array}{l}\text { HLS }\left(\mathrm{X}_{3}\right), \text { Pengeluaran Perkapita } \\
\left(\mathrm{X}_{4}\right)\end{array}$ & $\begin{array}{l}\text { AHH }\left(X_{1}\right), \text { RLS }\left(X_{2}\right), \text { Persentase Penduduk } \\
\text { Miskin }\left(X_{5}\right)\end{array}$ & \\
\hline 3 & $\begin{array}{l}\text { HLS }\left(\mathrm{X}_{3}\right) \text {, Pengeluaran Perkapita } \\
\left(\mathrm{X}_{4}\right), \mathrm{RLS}\left(\mathrm{X}_{2}\right)\end{array}$ & AHH $\left(X_{1}\right)$, Persentase Penduduk Miskin $\left(X_{5}\right)$ & \\
\hline 4 & $\begin{array}{l}\text { HLS }\left(\mathrm{X}_{3}\right) \text {, Pengeluaran Perkapita } \\
\left(\mathrm{X}_{4}\right), \mathrm{RLS}\left(\mathrm{X}_{2}\right), \text { AHH }\left(\mathrm{X}_{1}\right)\end{array}$ & Persentase Penduduk Miskin $\left(\mathrm{X}_{5}\right)$ & \\
\hline
\end{tabular}

Tabel 4 menunjukkan bahwa terdapat empat model regresi yang diperoleh dari empat tahapan pemilihan variabel prediktor yang memiliki nilai koefisien korelasi tertinggi. Diketahui model 1 melibatkan variabel Harapan Lama Sekolah, model 2 melibatkan variabel Harapan Lama Sekolah dan Pengeluaran Perkapita, model 3 melibatkan variabel Harapan Lama Sekolah, Pengeluaran Perkapita dan Rata-rata Lama Sekolah, serta model 4 melibatkan variabel Harapan Lama Sekolah, Pengeluaran Perkapita, Rata-rata Lama Sekolah dan Angka Harapan Hidup.

Tabel 5. ANOVA Metode Stepwise

\begin{tabular}{|c|c|c|c|c|c|c|}
\hline \multicolumn{2}{|r|}{ Model } & Jumlah Kuadrat & $\mathbf{d b}$ & Kuadrat Tengah & $\mathbf{F}$ & Sig. \\
\hline \multirow{3}{*}{1} & Regression & 13.422 & 1 & 13.422 & 290.203 & .000 \\
\hline & Residual & .278 & 6 & .046 & & \\
\hline & Total & 13.700 & 7 & & & \\
\hline \multirow{3}{*}{2} & Regression & 13.687 & 2 & 6.844 & 2806.409 & .000 \\
\hline & Residual & .012 & 5 & .002 & & \\
\hline & Total & 13.700 & 7 & & & \\
\hline \multirow{3}{*}{3} & Regression & 13.697 & 3 & 4.566 & 7674.962 & .000 \\
\hline & Residual & .002 & 4 & .001 & & \\
\hline & Total & 13.700 & 7 & & & \\
\hline \multirow{3}{*}{4} & Regression & 13.699 & 4 & 3.425 & 49550.403 & .000 \\
\hline & Residual & .000 & 3 & .000 & & \\
\hline & Total & 13.700 & 7 & & & \\
\hline
\end{tabular}

Variabel prediktor pada keempat model regresi yang terbentuk pada Tabel 4 merupakan variabel yang memiliki nilai koefisien korelasi tertinggi dan berpengaruh signifikan terhadap variabel respon. Hasil pengujian signifikansi parameter secara simultan dapat dilihat pada Tabel 5. Adapun hipotesis yang digunakan dalam pengujian simultan sebagai berikut [9].

1. Hipotesis model 1

$\mathrm{H}_{0}: \beta_{1}=0$

(Secarasimultan seluruh variabel prediktor tidak berpengaruh terhadap IPM)

$\mathrm{H}_{0}$ : minimal ada satu $\beta_{j} \neq 0$

(Secarasimultan seluruh variabel prediktor berpengaruh terhadap IPM)

2. Hipotesis model 2

$\mathrm{H}_{0}: \beta_{1}=\beta_{2}=0$

(Secara simultan seluruh variabel prediktor tidak berpengaruh terhadap IPM)

$\mathrm{H}_{0}$ : minimal ada satu $\beta_{j} \neq 0$

(Secara simultan seluruh variabel prediktor berpengaruh terhadap IPM)

3. Hipotesis model 3 
$\mathrm{H}_{0}: \beta_{1}=\beta_{2}=\beta_{3}=0$

(Secara simultan seluruh variabel prediktor tidak berpengaruh terhadap IPM)

$\mathrm{H}_{0}$ : minimal ada satu $\beta_{j} \neq 0$

(Secara simultan seluruh variabel prediktor berpengaruh terhadap IPM)

4. Hipotesis model 4

$\mathrm{H}_{0}: \beta_{1}=\beta_{2}=\beta_{3}=\beta_{4}=0$

(Secarasimultan seluruh variabel prediktor tidak berpengaruh terhadap IPM)

$\mathrm{H}_{0}$ : minimal ada satu $\beta_{j} \neq 0$

(Secarasimultan seluruh variabel prediktor berpengaruh terhadap IPM)

Berdasarkan Tabel 5, diperoleh nilai uji $\mathrm{F}$ untuk masing-masing model regresi dan signifikansi sebesar 0,000 lebih kecil dari taraf signifikansi 5\%. Oleh karena itu, pengujian hipotesis secara simultan untuk keempat model regresi tersebut diputuskan tolak $\mathrm{H}_{0}$ sehingga dapat disimpulkan bahwa minimal ada satu variabel prediktor yang berpengaruh signifikan terhadap Indeks Pembangunan Manusia (IPM).

Selanjutnya dilakukan pengujian signifikansi parameter secara parsial pada masing-masing model regresi untuk mengetahui variabel-variabel prediktor yang berpengaruh signifikan terhadap IPM. Hipotesis yang digunakan sebagai berikut [9].

$\mathrm{H}_{0}: \beta_{j}=0$

(Secara parsial variabel prediktor ke - $\mathrm{j}$ tidak berpengaru h terhadap IPM) $\mathrm{H}_{0}: \beta_{j} \neq 0$, dimana $j=1,2, \ldots, p$

(Secara parsial variabel prediktor ke - j berpengaru h terhadap IPM

Tabel 6. Hasil Uji Parsial Metode Stepwise

\begin{tabular}{|c|l|c|c|c|}
\hline \multicolumn{2}{|c|}{ Model } & Koefisien & t & Sig. \\
\hline \multirow{3}{*}{1} & (Constant) & 37.337 & 15.530 & .000 \\
\cline { 2 - 5 } & HLS $\left(\mathrm{X}_{3}\right)$ & 2.651 & 17.035 & $\mathbf{. 0 0 0}$ \\
\hline \multirow{3}{*}{2} & (Constant) & 36.482 & 65.367 & .000 \\
\cline { 2 - 5 } & HLS $\left(\mathrm{X}_{3}\right)$ & 1.642 & 15.921 & $\mathbf{. 0 0 0}$ \\
\cline { 2 - 5 } & Pengeluaran Perkapita $\left(\mathrm{X}_{4}\right)$ & .001 & 10.431 & $\mathbf{. 0 0 0}$ \\
\hline \multirow{4}{*}{3} & 35.548 & 99.043 & .000 \\
\cline { 2 - 5 } & Constant) & 1.309 & 13.577 & $\mathbf{. 0 0 0}$ \\
\cline { 2 - 5 } & HLS $\left(\mathrm{X}_{3}\right)$ & .001 & 19.326 & $\mathbf{. 0 0 0}$ \\
\cline { 2 - 5 } & Pengeluaran Perkapita $\left(\mathrm{X}_{4}\right)$ & .609 & 4.062 & $\mathbf{. 0 1 5}$ \\
\cline { 2 - 5 } & RLS $\left(\mathrm{X}_{2}\right)$ & 6.145 & 1.171 & .326 \\
\hline \multirow{4}{*}{4} & Constant) & .891 & 10.922 & $\mathbf{. 0 0 2}$ \\
\cline { 2 - 5 } & HLS $\left(\mathrm{X}_{3}\right)$ & .001 & 9.715 & $\mathbf{. 0 0 2}$ \\
\cline { 2 - 5 } & Pengeluaran Perkapita $\left(\mathrm{X}_{4}\right)$ & 1.137 & 10.612 & $\mathbf{. 0 0 2}$ \\
\cline { 2 - 5 } & RLS $\left(\mathrm{X}_{2}\right)$ & .511 & 5.606 & $\mathbf{. 0 1 1}$ \\
\cline { 2 - 5 } & AHH $\left(\mathrm{X}_{1}\right)$ & & & \\
\hline
\end{tabular}

Berdasarkan hasil pengujian signifikansi parameter secara parsial pada Tabel 6, diperoleh keputusan tolak $\mathrm{H}_{0}$ untuk semua model regresi. Artinya semua variabel prediktor pada keempat model regresi berpengaruh signifikan terhadap IPM. Hal tersebut dapat dilihat dari nilai signifikansi lebih kecil dari taraf signifikansi $5 \%$.

Setelah melalui tahapan pengujian signifikansi parameter secara simultan dan parsial, keempat model regresi dengan metode stepwise diuji multikolinearitas kembali untuk memastikan masalah linearitas antar variabel prediktor sudah teratasi. Nilai VIF variabel prediktor pada keempat model sebagai berikut. 
Tabel 7. Nilai VIF Variabel Prediktor Model Stepwise

\begin{tabular}{|c|l|c|}
\hline \multicolumn{2}{|c|}{ Model } & Nilai VIF \\
\hline \multirow{3}{*}{1} & $($ Constant $)$ & \\
\cline { 2 - 3 } & HLS $\left(\mathrm{X}_{3}\right)$ & $\mathbf{1 , 0 0 0}$ \\
\hline \multirow{4}{*}{2} & $($ Constant) & \\
\cline { 2 - 3 } & HLS $\left(\mathrm{X}_{3}\right)$ & $\mathbf{8 , 3 2 9}$ \\
\cline { 2 - 3 } & Pengeluaran Perkapita $\left(\mathrm{X}_{4}\right)$ & $\mathbf{8 , 3 2 9}$ \\
\hline \multirow{4}{*}{3} & (Constant) & \\
\cline { 2 - 3 } & HLS $\left(\mathrm{X}_{3}\right)$ & 29,858 \\
\cline { 2 - 3 } & Pengeluaran Perkapita $\left(\mathrm{X}_{4}\right)$ & 8,939 \\
\cline { 2 - 3 } & RLS $\left(\mathrm{X}_{2}\right)$ & 29,932 \\
\hline \multirow{4}{*}{4} & Constant) & 183,842 \\
\cline { 2 - 3 } & HLS $\left(\mathrm{X}_{3}\right)$ & 125,721 \\
\cline { 2 - 3 } & Pengeluaran Perkapita $\left(\mathrm{X}_{4}\right)$ & 131,492 \\
\cline { 2 - 3 } & RLS $\left(\mathrm{X}_{2}\right)$ & 174,974 \\
\cline { 2 - 3 } & AHH $\left(\mathrm{X}_{1}\right)$ & \\
\hline
\end{tabular}

Pada Tabel 7 dapat diketahui bahwa model 1 dan model 2 yang memiliki nilai VIF lebih kecil dari 10. maka diperoleh model terbaik yaitu model 2 dimana variabel prediktornya yaitu Harapan Lama Sekolah dan Pengeluaran Perkapita. Persamaan regresi linear berganda dengan metode stepwise yaitu.

$$
\hat{Y}=36,482+1,642 X_{3}+0,001 X_{4}
$$

Salah satu contoh menginterpretasikan koefisien regresi yaitu nilai 1,1642 memiliki arti, setiap penambahan $X_{3}$ (HLS) sebesar 1 satuan maka $\hat{Y}$ (IPM) akan bertambah sebesar 1,642 satuan dengan anggapan $X_{4}$ (Pendapatan Perkapita) konstan. Dapat juga diketahui nilai koefisien determinasi $\left(R^{2}\right)$ dari model regresi dengan metode stepwise pada Tabel 8.

Tabel 8. Koefisien Determinasi

\begin{tabular}{|c|c|c|}
\hline Model & $\boldsymbol{R}$ & $\boldsymbol{R}^{2}$ \\
\hline 2 & 0,990 & 0,980 \\
\hline
\end{tabular}

Nilai $R^{2}$ sebesar 0,980 menunjukkan bahwa Harapan Lama Sekolah dan Pengeluaran Perkapita dapat menjelaskan Indeks Pembangunan Manusia sebesar 98\% dari model regresi yang terbentuk.

\subsection{Pengujian Asumsi Klasik Regresi Linear}

Model regresi linear berganda yang diperoleh dengan metode stepwise kemudian melalui tahapan pengujian asumsi klasik regresi linear, yaitu uji normalitas, uji heteroskedastisitas dan uji autokorelasi.

\section{Uji Normalitas}

Penelitian ini menggunakan data dengan jumlah yang kecil sehingga pengujian normalitas menggunakan Shapiro-Wilk dengan hipotesis sebagai berikut [8]

$\mathrm{H}_{0}$ : residual berdistribusi normal

$\mathrm{H}_{1}$ : residual tidak berdistribusi normal

Hasil pengujian normalitas terhadap residual pada Tabel 9 menunjukkan nilai signifikan lebih dari taraf signifikansi $5 \%$ sehingga keputusan terima $\mathrm{H}_{0}$, artinya residual berdistribusi normal.

Tabel 9. Uji Normalitas

\begin{tabular}{|c|c|c|}
\hline $\boldsymbol{n}$ & Shapiro-Wilk & Sig \\
\hline 8 & 0,974 & 0,925 \\
\hline
\end{tabular}




\section{Uji Heteroskedastisitas}

Selanjutnya dilakukan pengujian heteroskedastisitas menggunakan uji Glejser dengan hipotesis sebagai berikut [9].

$\mathrm{H}_{0}$ : Tidak terjadi heteroskedastisitas

$\mathrm{H}_{1}$ : Terjadi heteroskedastisitas

Tabel 10 menunjukkan nilai signifikan Harapan Lama Sekolah dan Pengeluaran Perkapita lebih dari taraf signifikansi $5 \%$ sehingga keputusan terima $\mathrm{H}_{0}$, artinya tidak terjadi heteroskedastisitas.

Tabel 10. Uji Glejser

\begin{tabular}{|l|c|c|}
\hline \multicolumn{1}{|c|}{ Variabel } & t & Sig \\
\hline (Constant) & 0,000 & 1,000 \\
\hline HLS $\left(\mathrm{X}_{3}\right)$ & 0,000 & $\mathbf{1 , 0 0 0}$ \\
\hline Pengeluaran Perkapita $\left(\mathrm{X}_{4}\right)$ & 0,000 & $\mathbf{1 , 0 0 0}$ \\
\hline
\end{tabular}

\section{Uji Autokorelasi}

Pengujian autokorelasi manggunakan uji Durbin-Watson dengan hipotesis sebagai berikut [8]

$\mathrm{H}_{0}: \rho=0$ (tidak ada autokorela si pada residual)

$\mathrm{H}_{0}: \rho \neq 0$ (ada autokorela si pada residual)

Hasil pengujian autokorelasi terhadap residual pada Tabel 11 menunjukkan nilai Durbin-Watson sebesar 1,825, dimana nilai tabel Durbin-Watson $d_{L}=0,559$ dan $d_{U}=1,770$ dengan $n=8$ dan jumlah variabel bebas sebanyak 2. Karena nilai Durbin-Watson lebih besar dari $d_{\mathrm{U}}$ maka keputusan terima $\mathrm{H}_{0}$, artinya tidak ada autokorelasi pada residual.

Tabel 11. Uji Durbin Watson
\begin{tabular}{|c|c|}
\hline $\boldsymbol{R}^{\mathbf{2}}$ & Durbin-Watson \\
\hline 0,980 & 1,825 \\
\hline
\end{tabular}

\section{KESIMPULAN}

Kesimpulan yang diperoleh berdasarkan hasil dan pembahasan sebagai berikut.

1) Pemodelan Indeks Pembangunan Manusia kota Ambon menggunakan metode stepwise menghasilkan model terbaik, yaitu model regresi linear berganda yang tidak terdapat masalah multikolinearitas.

2) Diperoleh informasi bahwa harapan lama sekolah dan pengeluaran perkapita memberikan pengaruh yang signifikan terhadap Indeks Pembangunan Manusia dengan nilai $R^{2}$ sebesar $98 \%$.

3) Model terbaik Indeks Pembangunan Manusia kota Ambon menggunakan metode stepwise:

$$
\hat{Y}=36,482+1,642 X_{3}+0,001 X_{4}
$$

\section{DAFTAR PUSTAKA}

[1] W. Pratiwi. (2020, 23 Maret) Kuliah Pengantar: Indeks Pembangunan Sub Bidang Pembangunan Pedesaan Di Program Studi Arsitektur, ITB. [Online]. http://dosen.ar.itb.ac.id/wdp/wp-content/uploads

[2] Badan Pusat Statistik Provinsi Maluku, "Maluku dalam Angka”. Ambon, 2017.

[3] Badan Pusat Statistik Kota Ambon, "Kota Ambon dalam Angka”. Ambon, 2017. 
Latupeirissa, dkk| Pemodelan Indeks Pembangunan Manusia (IPM) . .

[4] S. B. Loklomin, "Pemodelan Indeks Pembangunan Manusia di Kepulauan Maluku dengan Pendekatan Estimasi Interval Parameter Model Regresi Semiparametrik Sline Truncataed," Barekeng, vol. vol 13, no $2,2019$.

[5] D. Gujarati, Ekonometrika Dasar. Sumarno Zain Penerjemah. Jakarta: Erlangga, 2004.

[6] S. C. Wohon, D. Hatidja, and N. Nainggolan, "Penentuan Model Regresi Terbaik dengan Menggunakan Metode Stepwise," Jurnal Ilmiah Sains, vol. vol 17, no 2, 2017.

[7] A. Haspery and R. R. A. Lubis, "Penggunaan Metode Stepwise pada Pemodelan Perencanaan Track Quality Index (TQI) Untuk Kereta Api Semicepat Indonesia," Mathematics Education, Science and Technology, vol. vol 4, no 1, Juli 2019.

[8] Setiawan and D. E. Kusrini, Ekonometrika.: Andi, 2010.

[9] N. D. Gujarati, Basic Econometrics, 4th, Ed. New York: McGraw-Hill Companies, Inc, 2003. 